\title{
Scientific publishing in the European research area
}

\author{
Por Fernanda Peset
}

Peset, Fernanda. "Scientific publishing in the European research area" (reseña). En: El profesional de la información, 2008, enero-febrero, v. 17, n. 1, p. 120.

DOI: $10.3145 /$ epi.2008.ene.16

RECIENTEMENTE LA $\mathrm{CO}$ MISIÓN EUROPEA ha distribuido la edición impresa de las actas de la conferencia sobre edición científica celebrada en Bruselas, 15-16 de febrero de $2007^{1}$.

Puede bajar gratuitamente de:

http://ec.europa.eu/research/ science-society/document_library/pdf_06/conference-proceeding022007_en.pdf

Cabe destacar dos aspectos de la conferencia. Lo primero que me resultó sorprendente fue la orientación de la mayoría de intervenciones -que pueden verse desarrolladas en el texto completo del libro de actashacia el Acceso Abierto, cuando en realidad el título de la conferencia se refería a la publicación científica en general.

Recordemos que depositar un trabajo en un archivo abierto no es sinónimo de publicarlo en el sentido estricto del término. Por tanto, aunque las revistas científicas siguen detentando su papel de certificadoras del conocimiento a través del sistema de evaluación por pares, parece que el movimiento de Acceso Abierto les preocupa.

De hecho, el esloveno Janez Potočnik, comisario para ciencia e investigación en la UE, mostró el interés de la Comisión en conciliar los intereses entre los editores científicos y el modelo de distribución abierto. El borrador de la directiva posterior de la Comisión Europea se fraguó en esa fecha y recogía este nuevo paradigma de difusión de la información científica² ${ }^{2}$ También en este sentido, Norbert Kroó, de la

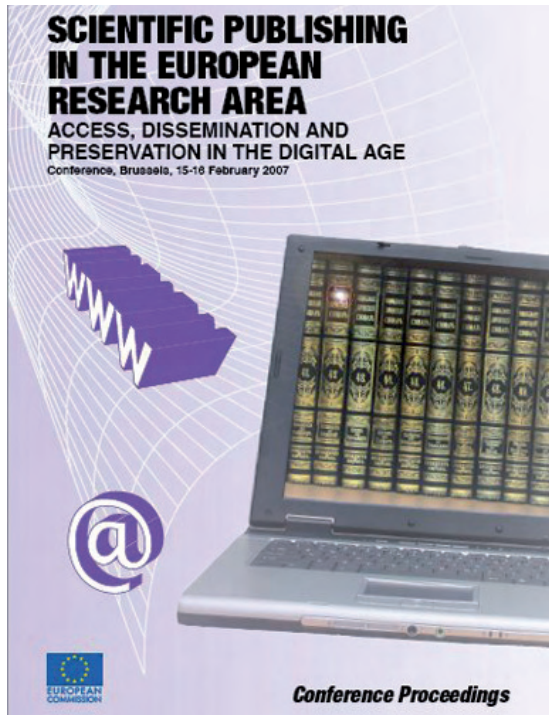

Academia Húngara de las Ciencias, recordó la Declaración del Consejo Europeo de Investigación sobre el Acceso Abierto $^{3}$. Los organismos financiadores no pueden soslayar los beneficios de las políticas que obligan a depositar los resultados de proyectos financiados con fondos públicos.

Resulta reconfortante que las más altas autoridades europeas y las grandes editoriales transnacionales acusen el impacto del movimiento de Acceso Abierto. El éxito de los múltiples proyectos que poco a poco conforman una malla tupida de contenidos científicos es el éxito de todas las personas -técnicos, autores, autoridades...- interesadas e involucradas en ellos.

El segundo aspecto que cabe destacar fue la cantidad de personas interesadas en el tema y su distinta procedencia. La representación española fue destacable, con Manuela Palafox (UCM), Alice Keefer (UB), Alicia López Me- dina (UNED), Remedios Melero (IATA), Ernest Abadal (UB), Francisca Abad (UV), Antonia Ferrer y yo misma (UPV).

\section{Notas}

1. Scientific publishing in the European research area: access, dissemination and preservation in the digital age: Conference, Brussels, 15-16 February 2007. Luxembourg: Office for Official Publications of the European Communities, 2007. ISBN 978-92-79-05476-1.

http://ec.europa.eu/research/science-society/ document_library/pdf_06/conference-proceeding-022007_en.pdf

2. Comisión de las Comunidades Europeas. Comunicación de la Comisión al Parlamento Europeo, al Consejo y al Comité Económico y Social Europeo sobre la información científica en la era digital: acceso, difusión y preservación: COM(2007) 56 final \{SEC(2007)181\}. Bruselas: CE, 14.2.2007

http://eur-lex.europa.eu/LexUriServ/site/es/ com/2007/com2007_0056es01.pdf

3. European Research Council. Scientific Council statement on open access. Bruselas: ERC, December 2006.

http://erc.europa.eu/pdf/open-access.pdf

Fernanda Peset, Universidad Politécnica de Valencia mpesetm@upv.es

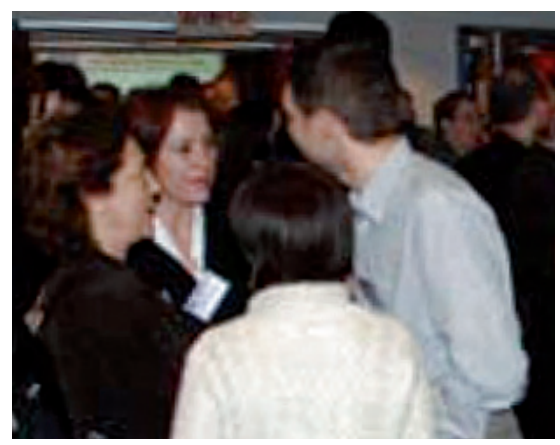

En la foto de la p. 19 de las actas oficiales distinguimos estos españoles: M. Palafox, R. Melero,

E. Abadal y M. F. Abad (de espaldas) 